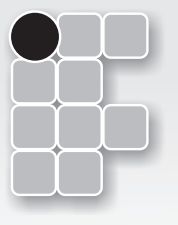

\title{
AVALIAÇÃO DA ÁREA DE DISPOSIÇÃO FINAL DE RESÍDUOS SÓLIDOS URBANOS NO MUNICÍPIO DE ARAGUARI UTILIZANDO O ÍNDICE DE QUALIDADE DE ATERROS DE RESÍDUOS - IOR
}

Luciana de Melo Pirete

Bruna Fernanda Faria Oliveira²

Maria da Graça Vasconcelos ${ }^{3}$

\section{Resumo}

A disposição final dos resíduos sólidos urbanos (RSU) tem se apresentado como um problema que as prefeituras têm dificuldade de equacionar, pois mesmo havendo incentivo à reutilização e reciclagem ainda existirão os remanescentes, conhecidos como rejeitos, que devem ser enviados aos aterros sanitários. Na maioria dos municípios brasileiros, a administração limita-se a recolher os resíduos domiciliares, depositando-os em locais afastados, sem maiores cuidados sanitários. A operação inadequada das áreas para deposição dos resíduos sólidos domiciliares, nos municípios, causa impactos ambientais e compromete a saúde pública. Nesse contexto, o presente trabalho teve como objetivo classificar a qualidade do aterro sanitário de Araguari (MG). Para isso foi realizada a aplicação do Índice de Qualidade de Aterro de Resíduos (IQR), que avalia os parâmetros referentes às características do local, à infraestrutura implantada e às condições operacionais do aterro, conforme a metodologia estabelecida pela Companhia de Tecnologia de Saneamento Ambiental (CETESB). Para isso foram realizadas inspeções locais, análise documental e entrevistas. Constatou-se que o aterro pode enquadrar-se em uma classe controlada, apesar da necessidade de ajustes em alguns itens.

Palavras-chave: Resíduos sólidos urbanos. Aterro sanitário. Qualidade ambiental. Meio Físico.

\section{Introdução}

O desenvolvimento industrial e tecnológico provocou o avanço da urbanização nos últimos 50 anos, principalmente no sudeste do país, região que concentra metrópoles e megalópoles com grande investimento técnico científico (SANTOS,2008). Este avanço provou o aumento do consumo da população, e, consequentemente, aumento da geração de resíduos, na maioria das vezes sem gerenciamento e destinação final adequado.

A má gestão dos resíduos sólidos causa impactos ambientais e compromete a saúde pública. Um exemplo disso é a geração do chorume que, quando não drenado e tratado, pode contaminar o solo e rios próximos através da lixiviação e de enxurradas, além de causar mau cheiro atraindo animais peçonhentos e vetores de doenças.

Com isso, a preocupação na busca de melhores alternativas e de soluções para o manejo dos resíduos é crescente e municípios com melhores gerenciamentos dos seus resíduos servem de exemplo para os demais, além de poderem receber premiações e/ou incentivos capazes de atrair empresas que fundamentam um serviço sustentável.

De acordo com os dados da Pesquisa Nacional de Saneamento Básico, (PNSB), realizada pelo Instituto Brasileiro de Geografia e Estatística(IBGE), em 2012, 23,7 milhões de toneladas dos resíduos sólidos urbanos foram destinados aos lixões e aterros controlados que constituem uma ameaça para a

${ }^{1}$ Estudante de graduação em Engenharia Ambiental; Instituto de Ciências Agrárias; Universidade Federal de Uberlândia; Uberlândia, MG. Email: lucianapirete@hotmail.com

${ }^{2}$ Professora de graduação; Instituto de Ciências Agrárias; Universidade Federal de Uberlândia; Uberlândia, MG.E-mail: brunafaria@iciag.ufu.br

${ }^{3}$ Pesquisadora; Instituto de Ciências Agrárias; Universidade Federal de Uberlândia; Uberlândia, MG. E-mail: mgvas@ufu.br 
população e para o meio ambiente, devido à geração de percolados e gases tóxicos. Porém, esta realidade tende a ser mudada, principalmente, com a Lei Federal n. ${ }^{\circ} 12.305$, aprovada em 2 de agosto de 2010,que determina a erradicação dos lixões nos municípios brasileiros.

Entre as formas de destinação e tratamento dos resíduos sólidos, o aterro sanitário é o mais empregado no Brasil, devido às questões econômicas e pela facilidade de operação. Esse método tende a confinar os resíduos e minimizar os impactos decorrentes do lixiviado e gás ali produzidos. Entretanto, minimizar não significa erradicar a poluição e mesmo aterros bem construídos e operados podem ser considerados empreendimentos potencialmente geradores de poluição.

$\mathrm{Na}$ tentativa de avaliar as condições do aterro que estão intimamente relacionadas à essa capacidade de poluição, a Companhia de Tecnologia de Saneamento Ambiental do Estado de São Paulo (CETESB), desenvolveu o Índice de Qualidade de Aterro de Resíduos(IQR), que avalia parâmetros que podem comprometer a qualidade do sistema.

Diante disso, o presente trabalho teve como objetivo principal avaliar a qualidade do aterro sanitário do município de Araguari/MG aplicando o IQR na área de estudo.

\section{Material e Métodos}

A avaliação do índice de qualidade de resíduos foi realizada utilizando a metodologia proposta pela Cetesb, em termos de características do local, infraestrutura e condições operacionais (CETESB, 2012). A coleta de dados para o IQR foi feita pelo preenchimento de um questionário padronizado, após a inspeção da unidade de disposição de resíduos, além de entrevistas com os responsáveis na manutenção e na operação do aterro sanitário, documentado por fotografias e gravações de áudios e vídeos.

\section{Caracterização da área de estudo}

O município de Araguari está situado na zona do Alto Paranaíba, Minas Gerais, fazendo parte da microrregião de Uberlândia e mesorregião Pontal do Triângulo Mineiro (CETEC, 2003).

A área do aterro sanitário encontra-se a leste do município, em uma região conhecida como Fazenda dos Verdes, cuja área equivale a 26 hectares e dista cerca de $7 \mathrm{~km}$ do centro urbano (CETEC, 2003). O aterro sanitário é propriedade da prefeitura municipal, sendo ela a responsável por todos os monitoramentos e operações no local, exceto pelas análises do sistema de tratamento do chorume e dos estudos da qualidade das águas subterrâneas e superficiais que são realizadas por uma empresa terceirizada. A geologia é constituída principalmente por material de origem basáltica e o solo apresenta textura arenosa, cascalho e argilosa.

Quanto à destinação dos resíduos, conforme dados da prefeitura, são coletadas em torno de 52 toneladas/dia, sendo retiradas cerca de 2,0 toneladas de resíduos recicláveis por dia, e dispondo cerca de 50 toneladas por dia no aterro em estudo (CETEC, 2003).

\section{Cálculo do IQR}

$\mathrm{Na}$ avaliação da qualidade ambiental do aterro sanitário de Araguari calculou-se o Índice de Qualidade de Aterro de Resíduo, IQR, cuja metodologia foi proposta pela CETESB, em função de critério composto por quarenta e uma variáveis, sendo estas divididas em três macro-conjuntos onde são consideradas as características do local (subtotal 1), a infraestrutura implantada (subtotal 2) e as condições operacionais do aterro (subtotal 3). Cada parâmetro avaliado apresenta um valor inserido no formulário que, ao ser somado, contribui para o cálculo do IQR. Com os valores obtidos pela somatória de todos os parâmetros de cada subtotal determina-se o valor do IQR a partir da fórmula apresentada na equação 1 .

$$
\mathrm{IQR}=\frac{\text { subtotal } 1+\text { subtotal } 2+\text { subtotal } 3}{13} \quad \text { (equação } 1 \text { ) }
$$

O formulário, assim constituído, quando preenchido, permite alcançar uma nota que enquadra as instalações de destinação final de resíduos urbanos em três condições apresentadas na tabela 1. 
Tabela 1: Classificações do local de estudo através do cálculo do IQR.

\begin{tabular}{|c|c|}
\hline Intervalos dos valores do IQR & Classificações do aterro sanitário \\
\hline 0,0 a 6,0 & Inadequadas \\
\hline 6,1 a 8,0 & Controladas \\
\hline 8,1 a 10,0 & Adequadas \\
\hline
\end{tabular}

Fonte: Companhia Tecnológica de Saneamento Ambiental (CETESB)

\section{Resultados e Discussão}

O aterro sanitário é composto por três células, sendo que apenas a primeira está em operação. Para o cálculo do IQR, foram avaliadas a característica do local, infraestrutura implantada e as condições operacionais, respectivamente. Assim, seguem os resultados das análises de cada item.

\section{Características do local}

A composição do solo é constituída por camadas de sedimentos arenosos, argilosos e basálticos. Esta foi testada por ensaios de permeabilidade a carga variável resultando a um coeficiente de permeabilidade equivalente a $10^{-6} \mathrm{~cm} / \mathrm{s}$.

A disponibilidade do material para recobrimento obteve uma avaliação insuficiente, movido pela dificuldade da aquisição do mesmo pela prefeitura municipal; na visita foi observada alta quantidade de resíduos descobertos, conforme a figura 1 .

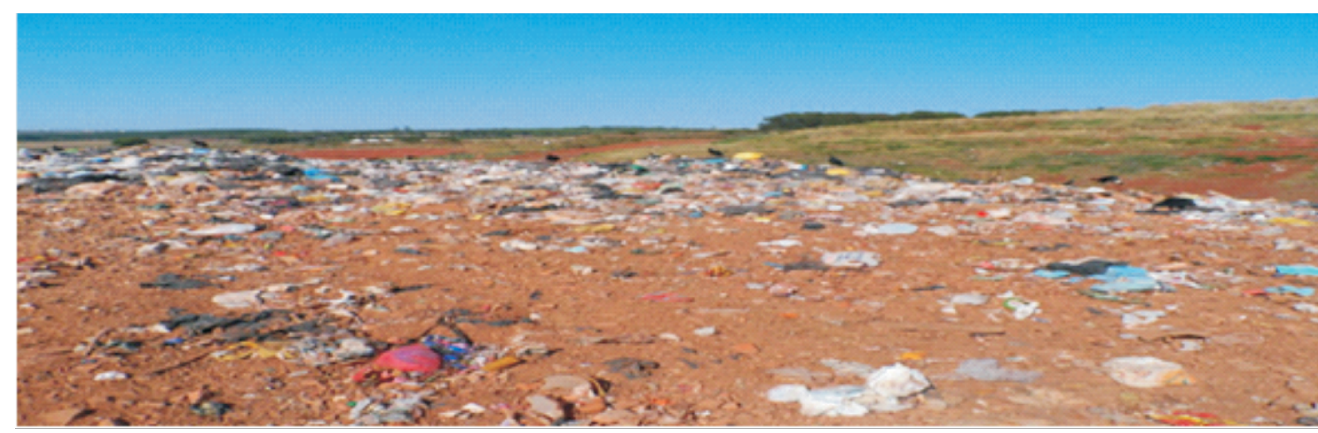

Figura 1: Resíduos descobertos pela falta de material para recobrimento.

Fonte: Elaboração do autor

As condições viárias são regulares, e por não serem pavimentadas em épocas chuvosas a circulação dos maquinários é dificultada, conforme a figura 2.

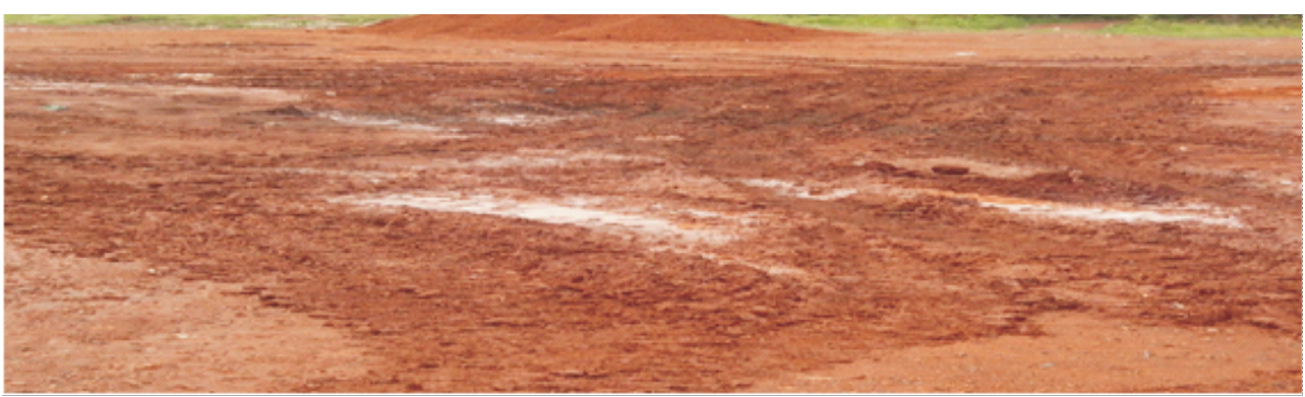

Figura 2: Sistema viário sob más condições em épocas de chuvas.

Fonte: Elaboração do autor 
A tabela 2 apresenta os critérios avaliados quanto à característica do local e seus respectivos valores obtidos.

Tabela 2: Critérios avaliados quanto à característica do local.

\begin{tabular}{|c|c|c|}
\hline $\begin{array}{c}\text { ÍNDICE DE QUALIDADE DE ATERRO DE } \\
\text { RESIIDUOS - IQR }\end{array}$ & & \\
\hline Características do local & & \\
\hline $\begin{array}{l}\text { SUBITEM } \\
\end{array}$ & AVALIAÇÃO & VALOR \\
\hline Capacidade de suporte & Adequada & 5 \\
\hline Proximidade dos núcleos habitacionais & $>500 \mathrm{~m}$ & 5 \\
\hline Profundidade de corpos d'água & $>200 \mathrm{~m}$ & 3 \\
\hline Permeabilidade do lençol freático & 1 a $3 \mathrm{~m}$ & 2 \\
\hline Permeabilidade do solo & Baixa & 5 \\
\hline Disponibilidade do material para recobrimento & Insuficiente & 2 \\
\hline Qualidade do material para recobrimento & Boa & 2 \\
\hline Condição do sistema viário & Regular & 2 \\
\hline Isolamento visual & Bom & 4 \\
\hline Legalização da localização & Permitido & 5 \\
\hline $\begin{array}{l}\text { Subtotal } 1 \\
35\end{array}$ & & \\
\hline
\end{tabular}

Fonte: Companhia Tecnológica de Saneamento Ambiental (CETESB)

O material destinado ao aterro sanitário são resíduos sólidos urbanos da cidade de Araguari(MG), sendo a operação do aterro realizada pela Prefeitura Municipal que utiliza para isso um trator de esteira, pá carregadeira, caminhão-pipa e uma moto-niveladora.

A drenagem do chorume é feita por canalizações internas do aterro sanitário, apresentadas na figura 3, que direcionam o líquido percolado a uma estação de tratamento enquanto que a drenagem de águas pluviais é feita por canaletas externas, apresentadas na figura 4, que conduzem o líquido pluvial até o Córrego Brejo Alegre, situado próximo ao aterro sanitário e de maneira que não haja contato com o chorume (CETEC, 2003).

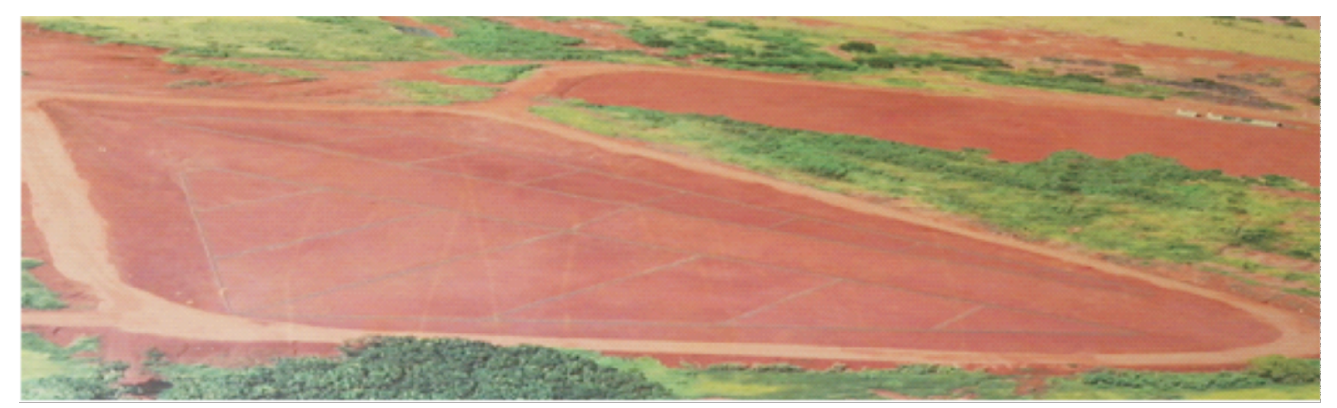

Figura 3: Canalizações internas de drenagem do chorume do aterro sanitário.

Fonte: Elaboração do autor

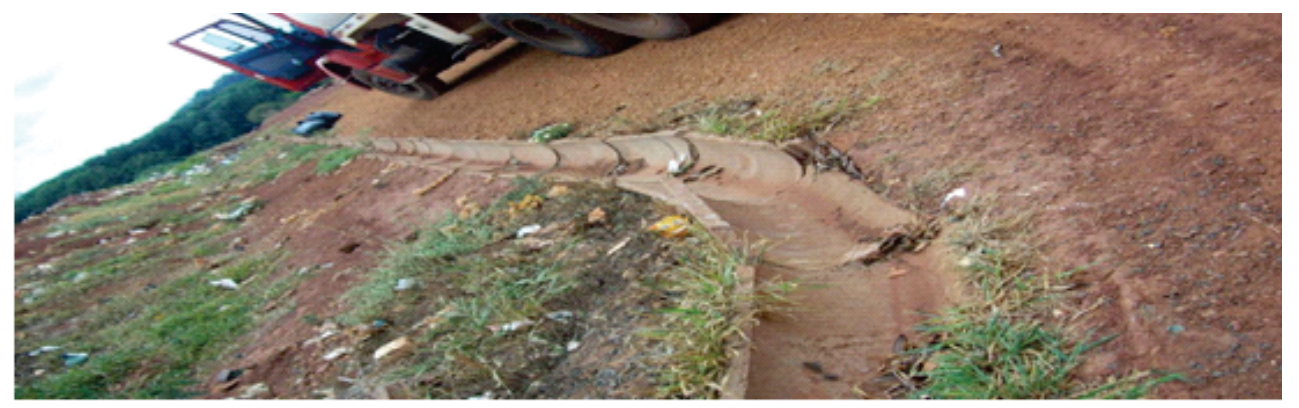

Figura 4: Canaletas que drenam águas pluviais do aterro sanitário.

Fonte: Elaboração do autor 
A coleta e as análises físico-químicas do chorume e das águas superficiais e subterrâneas são realizadas pela empresa Naturália,localizada no município de Araxá/MG. O tratamento do chorume é feito em lagoas anaeróbias seguidas de lagoas facultativas, figura 5, implantadas em etapas, esse sistema adota como premissa menores custos de operação, remoção da demanda bioquímica de oxigênio (DBO) e resistência a variações de carga, segundo o plano de controle ambiental do aterro sanitário.

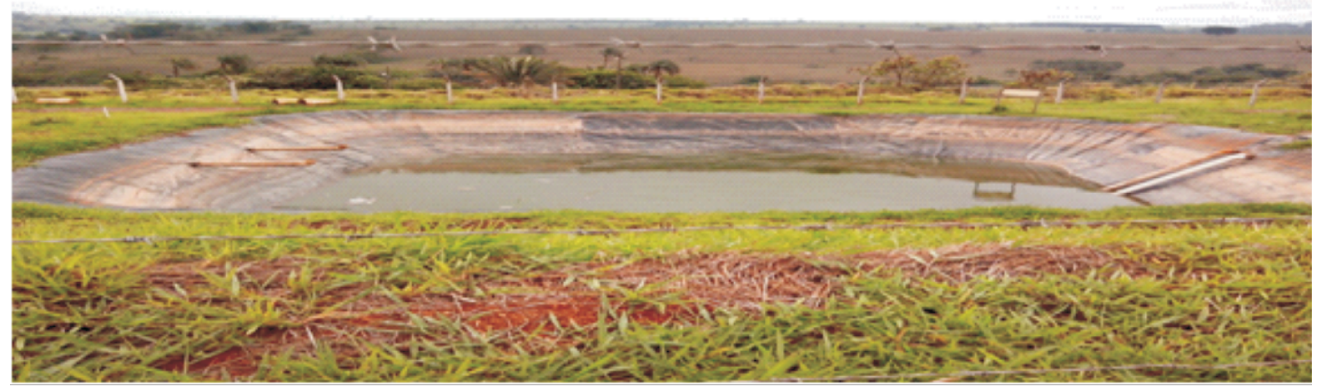

Figura 5: Lagoa de tratamento facultativo do chorume do aterro sanitário.

Fonte: Elaboração do autor

Na recepção, existem pessoas responsáveis pela vigilância do local, e o controle de cargas é feito por uma balança rodoviária da Cooperativa dos Produtores de Grãos de Araguari, sendo pesados e monitorados diariamente por um responsável, figura 6.

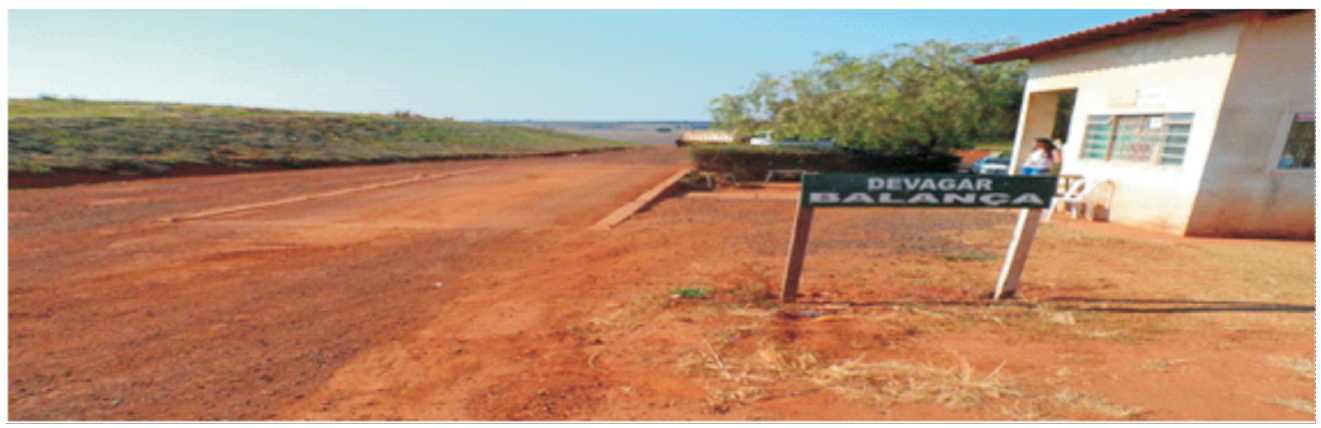

Figura 6: Balança para o controle de cargas no aterro sanitário.

Fonte: Elaboração do autor 
A tabela 3 apresenta os critérios avaliados quanto à infraestrutura implantada e seus valores obtidos.

Tabela 3: Critérios avaliados quanto à infraestrutura implantada.

\begin{tabular}{|c|c|c|}
\hline $\begin{array}{c}\text { ÍNDICE DE QUALIDADE DE ATERRO DE } \\
\text { RESIIDUOS - IQR } \\
\text { Infraestrutura implantada }\end{array}$ & & \\
\hline SUBITEM & AVALIAÇÃO & VALOR \\
\hline Cercamento da área & Sim & 2 \\
\hline Portaria/Guarita & Sim & 2 \\
\hline Impermeabilização de base & Sim & 5 \\
\hline Drenagem do chorume & Suficiente & 5 \\
\hline Drenagem águas pluviais definitivas & Insuficiente & 2 \\
\hline Drenagem águas pluviais provisórias & Suficiente & 2 \\
\hline Trator de esteira & Permanente & 5 \\
\hline Outros equipamentos & Sim & 1 \\
\hline Sistema de tratamento de chorume & Suficiente & 5 \\
\hline Acesso à frente do trabalho & Ruim & 0 \\
\hline Vigilantes & Sim & 1 \\
\hline Drenagem de gases & Suficiente & 3 \\
\hline Controle de cargas & Sim & 2 \\
\hline Monitoramento de águas subterrâneas & Suficiente & 3 \\
\hline Atendimento ao projeto & Parcialmente & 1 \\
\hline $\begin{array}{l}\text { Subtotal } 2 \\
35\end{array}$ & & \\
\hline
\end{tabular}

Fonte: Companhia Tecnológica de Saneamento Ambiental (CETESB)

\section{Condições operacionais}

Durante a visita ao local, foram observadas grande quantidade de aves, especialmente urubus, além da presença de outros animais como gados que são mostrados nas figuras 7 e 8 , respectivamente.

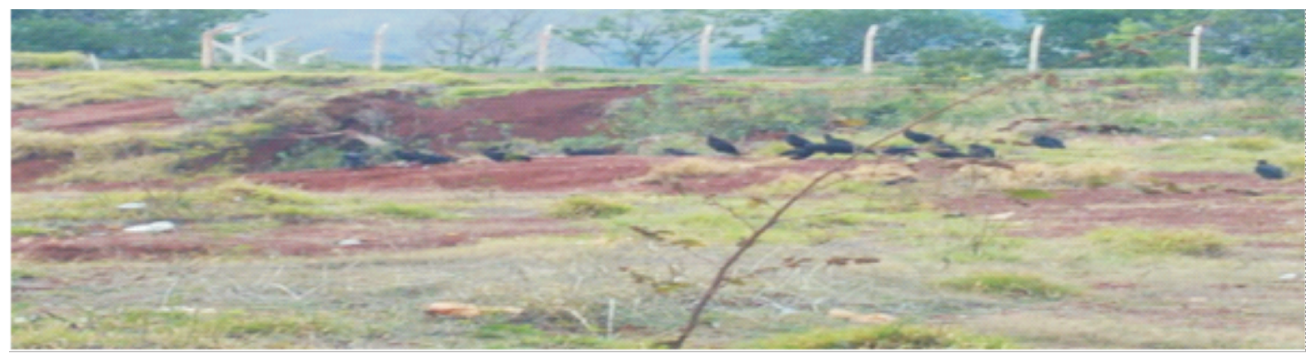

Figura 7: Presença de urubus no aterro sanitário.

Fonte: Elaboração do autor

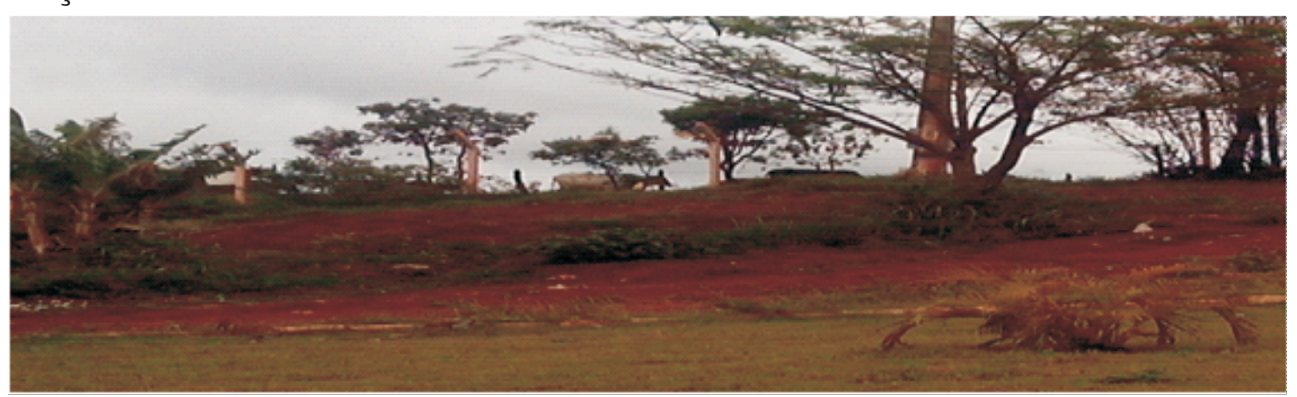

Figura 8: Presença de gados no aterro sanitário.

Fonte: Elaboração do autor 
A manutenção do acesso interno foi avaliada como regular, pois o cercamento da área é insuficiente apesar de apresentar guarita na recepção.

A tabela 4 apresenta os critérios avaliados quanto a condições operacionais do aterro e seus valores obtidos.

Tabela 4: Critérios avaliados quanto à condições operacionais.

\begin{tabular}{|c|c|c|}
\hline $\begin{array}{l}\text { ÍNDICE DE QUALIDADE DE ATERRO DE } \\
\text { RESÍDUOS - IQR }\end{array}$ & & \\
\hline Condições operacionais & & \\
\hline SUBITEM & AVALIAÇÃO & VALOR \\
\hline Aspecto geral & Bom & 4 \\
\hline Lixo a descoberto & Sim & 0 \\
\hline Recobrimento do lixo & Inadequado & 1 \\
\hline Urubus & Sim & 0 \\
\hline Moscas & Não & 2 \\
\hline Catadores & Não & 3 \\
\hline Criação de animais & $\operatorname{sim}$ & 0 \\
\hline Descarga de RSS & Sim & 0 \\
\hline Resíduos industriais & Não & 4 \\
\hline Drenagem Pluvial definitiva & Bom & 2 \\
\hline Drenagem Pluvial provisória & Regular & 1 \\
\hline Manutenção do acesso interno & Regular & 1 \\
\hline Drenagem de chorume & Bom & 3 \\
\hline Tratamento de chorume & Bom & 5 \\
\hline Monitoramento de água subterrânea & Bom & 2 \\
\hline Equipe de vigilância & Boa & 1 \\
\hline $\begin{array}{c}\text { Subtotal } 3 \\
30\end{array}$ & & \\
\hline
\end{tabular}

Fonte: Companhia Tecnológica de Saneamento Ambiental (CETESB)

\section{Cálculo do IQR}

As tabelas 2, 3 e 4 apresentam os valores atribuídos a cada um dos subitens do formulário com os quais pode-se determinar o IQR, apresentado na equação 2 .

$$
\left.\mathrm{IQR}=\frac{35+35+30}{13}=7,7 \quad \text { (equação } 2\right)
$$

Assim, de acordo com os dados levantados nas tabelas 2, 3 e 4, a qualidade do aterro sanitário de Araguari (MG) expressa condições controladas.

\section{Conclusões}

A classificação atingida pelo IQR demonstra que o aterro sanitário de Araguari (MG) expressa condições controladas em relação às características do local, infraestrutura implantada e às condições operacionais. No entanto, através do estudo realizado, constatou-se que as condições das vias de acesso, acesso à frente de trabalho, recobrimento dos resíduos e a manutenção dos acessos internos podem ser melhorados, fazendo com que os itens elevem a sua pontuação tornando as condições estruturais e operacionais do aterro adequadas.

Com algumas adaptações, o aterro sanitário poderá atender a maioria das exigências, tornar-se adequado e reduzir os riscos de contaminação dos solos e águas do entorno. 


\section{Referências Bibliográficas}

BRASIL. Presidência da República. Lei n. ${ }^{\circ} 12.305$ de 02 de agosto de 2010. Institui a Política Nacional de Resíduos Sólidos e altera a lei n. ${ }^{\circ} 9.605$ de 12 de fevereiro de 1998. Diário Oficial [da] República Federativa do Brasil, Poder legislativo, Brasília, DF, DIA DA PUBLICÃO, 2010.

COMPANHIA DE TECNOLOGIA DE SANEAMENTO AMBIENTAL - CETESB. Inventário Estadual de Resíduos Sólidos Domiciliares 2011. São Paulo. 2013.

Companhia de tecnologia de Saneamento Ambiental - CETESB. Panorama dos Resíduos Sólidos no Brasil 2012. São Paulo. 2014.

ECO 2 CITIES - ECOLOGICAL CITIES AND ECONOMIC CITIES.World Bank, 2009. Disponível em: <http://www.unep.org/greeneconomy/SuccessStories/SustainaibleUrbanPlanningBrazil/tabid/29867/ Default.aspx> . Acesso em: 15 março 2014.

FUNDAÇÃO CENTRO TECNOLÓGICO DE MINAS GERAIS - CETEC (MG).Plano de Controle Ambiental - PCA - Aterro Sanitário de Araguari. Belo Horizonte, MG. 2003.

INSTITUTO BRASILEIRO DE GEOGRAFIA E ESTATÍSTICA (IBGE). Cidades, 2010. Disponível em: http://cidades.ibge.gov.br/painel/historico.php?lang $=\&$ codmun $=310350 \&$ search $=$ minasgerais |araguari |infograficos:-historico. Acesso em: 15 março 2014.

INSTITUTO DE PESQUISAS TECNOLÓGICAS DO ESTADO DE SÃO PAULO (IPT). Lixo Municipal: manual de gerenciamento integrado. D'ALMEIDA, M. L. O.; VILHENA, A. (Coords.) 2. ed. São Paulo: IPT/CEMPRE, 2000.

MATHIEU, M. A., MELLO N. A. Gestão ambiental urbana, diferente em cidades planejadas? 0 caso de três cidades brasileiras. Confins, 2008, disponível em: http://confins.revues.org/5152. Acesso em: 15 março 2014.

SANTOS, M. A. Urbanização Brasileira. 5. ed São Paulo: Editora da Universidade de São Paulo, 2008. p. 63-68. 